Original Research Article

\title{
A prospective observational study on drug utilization pattern in medical intensive care unit of a tertiary medical care hospital
}

\author{
Divyashree C. R. ${ }^{1 *}$, Nalini G. K. ${ }^{1}$, Suresh R. M. ${ }^{2}$, Deepak P. ${ }^{1}$, Sahana G. N. ${ }^{1}$, \\ Jayashree V. Nagaral ${ }^{1}$, Mohith N. ${ }^{1}$, Rakshitha B. V. ${ }^{1}$
}

${ }^{1}$ Department of Pharmacology, ${ }^{2}$ Department of Medicine, Hassan Institute of Medical Sciences, Karnataka, India

Received: 04 April 2019

Revised: 12 April 2019

Accepted: 03 May 2019

*Correspondence to: Dr. Divyashree C. R., Email: divyashree.c.ramesh@ gmail.com

Copyright: () the author(s), publisher and licensee Medip Academy. This is an openaccess article distributed under the terms of the Creative Commons Attribution NonCommercial License, which permits unrestricted noncommercial use, distribution, and reproduction in any medium, provided the original work is properly cited.

\begin{abstract}
Background: Drug utilization research is a part of Pharmacoepidemiology defined by the WHO as the study of marketing, distribution, prescription, and use of drugs in a society, with special emphasis on the resulting medical, social and economic consequences. Conducting periodic studies of pattern of drug use in our hospital setting is essential to critically analyse the current hospital drug policies and to make recommendations based on various guidelines to improve upon the current drug usage pattern. Aims and objectives of the study was to generate data on the drug utilization pattern in Medical ICU and to monitor antimicrobial usage in MICU.
\end{abstract}

Methods: Patients who were admitted in medical ICU of Hassan institute of Medical Sciences were recruited based on inclusion-exclusion criteria. The study was conducted over a period of 3 months from April 2018 to June 2018. The demographic and clinical treatment data of patients were collected. The prescriptions were assessed as per the WHO indicators.

Results: Common causes of admission were suicidal poisoning, snake bite, viral thrombocytopenia, myocardial infarction and stroke. The average duration of stay was 5.74 days and average number of drugs/patient was 5.26. Pantoprazole, Ranitidine, Ceftriaxone, Atropine, Pralidoxime, ASV, Ondansetron, and Nacetylcysteine were commonly prescribed drugs. $42.4 \%$ of drugs were prescribed by generic names and $84.2 \%$ of the drugs were prescribed from Essential Medicine List.

Conclusions: This study will provide database to address prescription protocols and guide appropriate use of drugs in the ICU setting.

Keywords: Drug utilization, Intensive care, Pharmacoepidemiology, Prescription pattern, Tertiary care, WHO indicators

\section{INTRODUCTION}

Drug utilization study has been defined by the World Health Organization (WHO) as "The marketing, distribution, prescription and uses of drugs in a society with special emphasis on the resulting medical and social and economical consequences."

These studies are of help in determining the rationality of the prescribed drugs and also help in formulating evidence-based guideline for making policy decisions at various levels of health care system.
It is considered as a vital tool to study the clinical use of drugs in population and also its impact on the health-care system. Drug utilization patterns have been found to differ not only among different countries but, also within a country in different institutions and also in the same institution. Therefore, it is necessary to assess the drug utilization pattern of the patients to analyze the current hospital drug prescribing practices and make improvements based on various standard guidelines of treatment, thus, improving the future drug usage. This is particularly important in a resource poor country like ours so as to ensure stringent use of available resources., ${ }^{2,3}$ 
The intensive care unit (ICU) is a setting where most patients with serious diseases are admitted. Therefore, a large number of drugs are employed to save these patients and that make them susceptible to medication errors and adverse drug reactions. ${ }^{4}$ Since patients admitted to the ICU receive multiple drugs, the majority of these drugs are empirically prescribed and mainly in the physician's previous experience resulting in the lack of quantitative precision of drugs usage. ${ }^{5}$ Prescribing drugs is an important skill which needs to be continuously assessed and refined accordingly. ${ }^{6}$ The study of prescribing patterns seeks to monitor, evaluate and suggest modifications in practitioners' prescribing habits so as to make medical care rational. Information about antibiotic use patterns is necessary for a constructive approach to problems that arise from the multiple antibiotics available. ${ }^{7}$

With this state of affairs of varying drug usage patterns, we planned to study the drug utilization pattern of prescriptions dispensed to the patients admitted at our Institution's Medical ICU.

Aims and Objectives of this study was to generate data on the drug utilization pattern in Medical ICU, to monitor antimicrobial usage in MICU and to monitor and report the adverse drug reactions if any were encountered during the study period.

\section{METHODS}

The present study was an observational, prospective, drug utilization survey conducted at the MICU of Hassan Institute of medical Sciences, a tertiary care government teaching hospital. Prior permission was obtained from Institutional Ethics committee and Head of Medicine department to conduct the study. Our study duration was 3 months (April 2018 to June 2018).

An appropriate study protocol was developed, discussed and edited after consulting with the Pharmacology and General Medicine department heads.

\section{Selection criteria of the participants}

\section{Inclusion criteria}

- Adult patients above 18 years of age and of either gender who were admitted in Medical Intensive Care Unit.

- Those patients or their relatives who gave consent and were willing to participate in this study.

\section{Exclusion criteria}

- Patients who denied to consent to access their case records.

- Lactating and pregnant women.

The 220 cases were analysed. Inclusion exclusion criteria was applied and 200 cases were recruited into the study.
The WHO drug indicators that were selected to analyze the prescribing pattern were:

- Average number of the antimicrobial drugs prescribed per encounter.

- Percentage of the antimicrobial drugs prescribed by generic name.

- Percentage of the antimicrobial drugs prescribed from essential drug list.

- Frequency of antimicrobial drugs usage as per patient.

- Most common cause for admission in ICU.

\section{Statistical analysis}

The data was entered into Microsoft Excel sheet and descriptive statistics was applied to deduce results.

\section{RESULTS}

\section{Characteristics of study participants}

Out of total 200 patients, percentage of female and male patients was $31.5 \%$ and $68.5 \%$ respectively (male $=137$, female $=63$ ). The distribution of age among the study subjects is shown in Table 1 .

Table 1: Distribution of different age groups.

\begin{tabular}{|ll|}
\hline Age & No. of patients \\
\hline $18-25$ & 34 \\
\hline $26-35$ & 28 \\
\hline $36-45$ & 26 \\
\hline $46-55$ & 44 \\
\hline $56-65$ & 32 \\
\hline $66-75$ & 28 \\
\hline $76-85$ & 8 \\
\hline
\end{tabular}

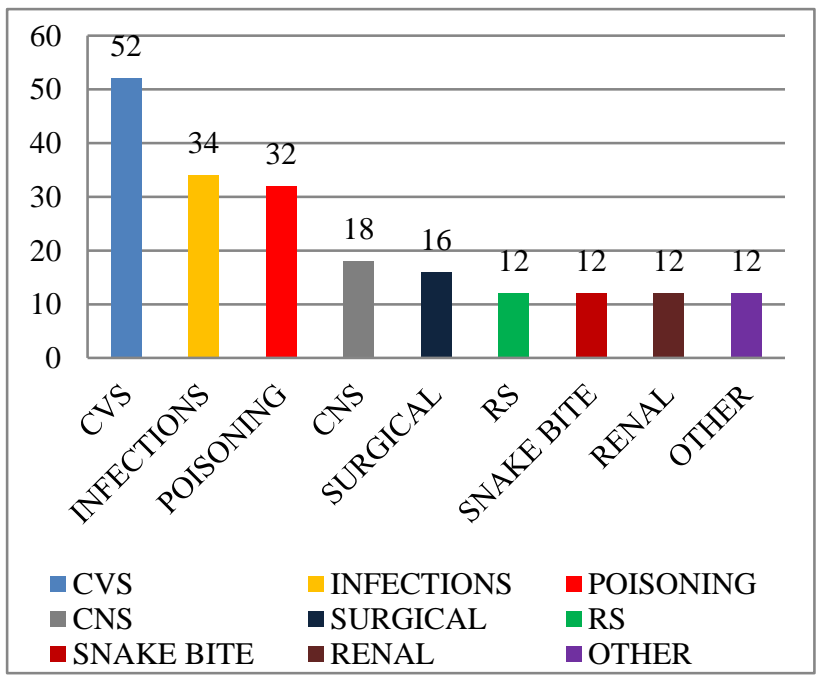

Figure 1: System wise classification of study subjects. 
Majority of the patients admitted were of cardiac causes followed by infectious causes, poisoning, CNS causes, surgical complications etc. The percentage distribution of the diagnosis in detail is described in Figure 1 and Table 2.

Table 2: Diagnosis of patients admitted in ICU.

\begin{tabular}{|ll|}
\hline Diagnosis & $\begin{array}{l}\text { Number of } \\
\text { patients }\end{array}$ \\
\hline Accelerated hypertension & 6 \\
\hline $\begin{array}{l}\text { Accelerated hypertension + } \\
\text { uncontrolled DM }\end{array}$ & 2 \\
\hline Anterior wall MI & 2 \\
\hline $\begin{array}{l}\text { Acute exacerbation of rheumatoid } \\
\text { arthritis }\end{array}$ & 4 \\
\hline Inferior wall MI & 4 \\
\hline Acute exacerbation of COPD & 10 \\
\hline Alcoholic liver disease & 2 \\
\hline Menorrhagia & 2 \\
\hline Severe anaemia & 6 \\
\hline P/O status appendicitis & 2 \\
\hline Atrial fibrillation & 8 \\
\hline $\begin{array}{l}\text { Blunt trauma chest with massive Rt } \\
\text { hemopneumothorax, s/c emphysema }\end{array}$ & 2 \\
\hline Ca Cervix stage 4 & 2 \\
\hline Unstable Angina & 2 \\
\hline CKD & 12 \\
\hline Complete heart block & 2 \\
\hline CVA & 2 \\
\hline Dilated cardiomyopathy & 2 \\
\hline Dengue with thrombocytopenia & 6 \\
\hline Diabetic ketoacidosis & 2 \\
\hline Status epilepticus & 6 \\
\hline Duodenal perforation & 6 \\
\hline IHD/CCF & 6 \\
\hline Kerosene poisoning & 2 \\
\hline Lateral wall MI & 4 \\
\hline LRTI & 2 \\
\hline Meningitis & 2 \\
\hline OP poisoning & 2 \\
\hline PUJ obstruction, post op status & 2 \\
\hline Old MI, status post CABG & 2 \\
\hline Rat poison consumption & 2 \\
\hline Septicemia + MODS & 2 \\
\hline Snake bite & 2 \\
\hline Status asthmaticus & 2 \\
\hline NSTMI & 2 \\
\hline
\end{tabular}

Most commonly prescribed drug group was gastrointestinal drugs $(18.42 \%)$, followed by antimicrobials (17.49\%) and CVS drugs (9.44\%).

Other drugs were ionotropes, poison antidotes such as atropine, ASV, PAM, IV fluids, tranexemic acid, vaccines such as tetanus toxoid etc. The distribution of system wise drugs according to their percentages is depicted in the Figure 2.

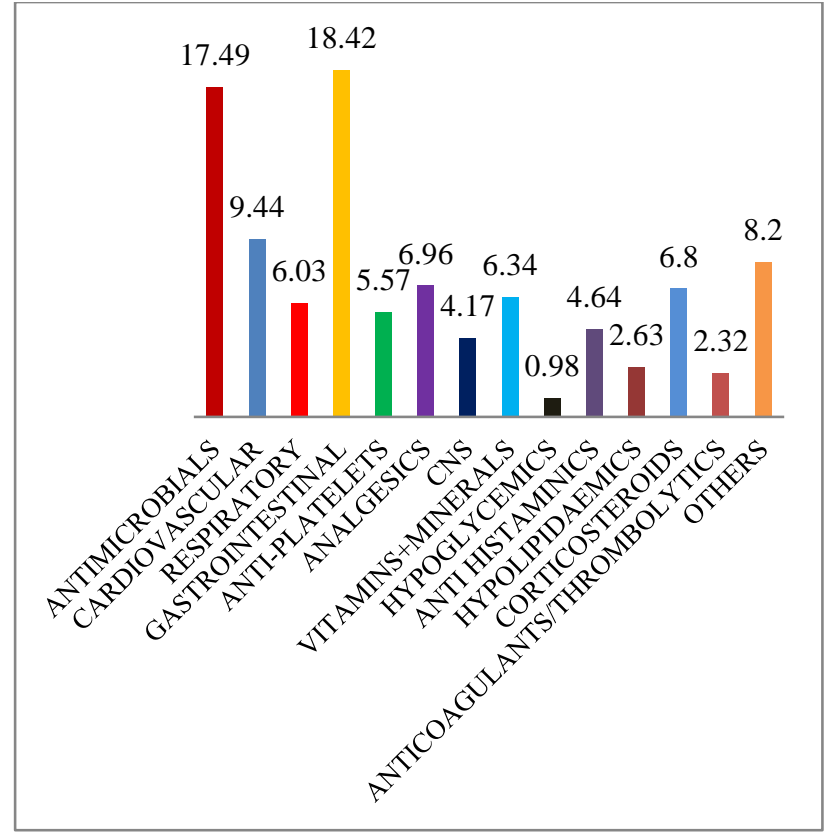

Figure 2: Classes of drugs prescribed in the intensive care unit.

The most commonly prescribed antimicrobial drug at our setting was found to be Ceftriaxone which was received by almost $61 \%$ of the study population, followed by Metronidazole (10\%). Rarely used antimicrobials were Amoxicillin, Linezolid, Cefixime, Vancomycin, Levofloxacin and Albendazole. Percentage distribution of the antimicrobial agents are shown in Figure 3 in detail.

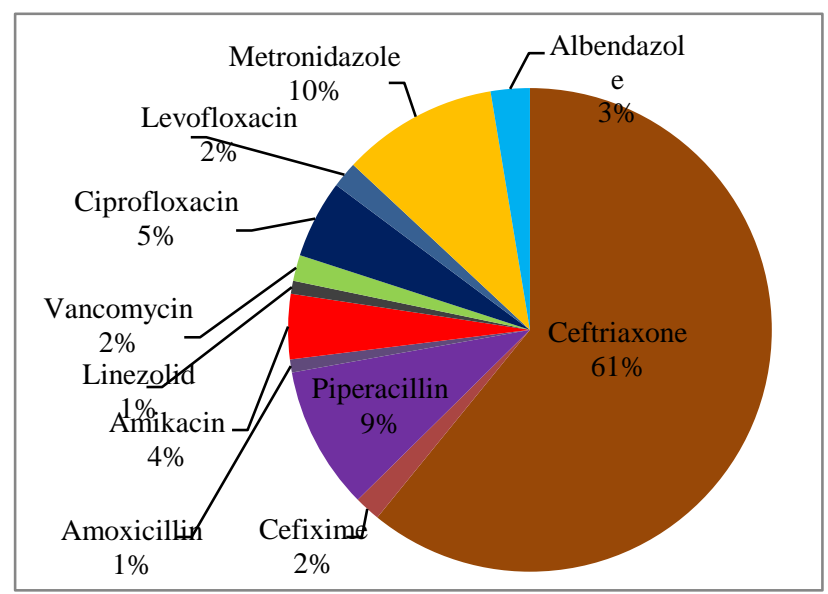

Figure 3: Commonly prescribed antimicrobials.

Analysis of prescription patterns according to various WHO drug use indicators.

- Frequency of antimicrobial usage per patient:

- 1 drug = 104 subjects

- 2 drugs $=44$ subjects

- 3 drugs $=8$ subjects

- 4 drugs $=6$ subjects 
- $\quad$ Average number of antimicrobials/encounter $=2.5$

- Antimicrobials prescribed by generic name $=26.89 \%$

- Antimicrobials prescribed from essential drug list $=$ $90.9 \%$

- Total number of drugs/patient $=2-16$

- Average duration of stay $=5.74$ days

- $\quad$ Average number of drugs per encounter $=6.68$

- Drugs prescribed from essential drug list $=84.2 \%$

- Drugs prescribed by generic name $=42.4 \%$.

\section{DISCUSSION}

In our study, a male preponderance $(68.5 \%)$ was observed which was similar to that of other studies. ${ }^{8-10}$

The most common indications for admission at our centre were cardiovascular system related $(26 \%)$ such as myocardial infarction, angina pectoris and various systemic infections (17\%) and poisonings (16\%) like organophosphorous compound consumption, kerosene poisoning, iron and folic acid poisoning and rat poison consumption. These findings were comparable to other studies. $^{2,11,12}$

It was observed that average number of antimicrobial drugs prescribed per patient in our study was 2.5 , which was similar to other studies where average number of prescribed antimicrobial drug was 3.36 and 2.09 respectively. ${ }^{13,14}$

It was observed that totally $42.4 \%$ of the drugs were prescribed by their generic names and $57.6 \%$ were prescribed by brand names at our institution. Antibiotics prescribed by their generic names were $26.89 \%$. Other studies showed varying results like $70 \%$ and $57.26 \%$. $^{14,15}$ A study conducted in Kuwait was comparable to ours with $24 \%$ antimicrobials being prescribed by generic name. ${ }^{16}$ The possible reason for broad utilisation of trade names even after amendment passed by the government may be because it was shorter than the generic names and supply of drugs with brand names.

Ceftriaxone was the most commonly used antimicrobial $(61 \%)$ at our centre while in other studies its usage was $17.23 \%$ and $12.6 \%$ respectively. ${ }^{15,17}$ It was followed by metronidazole (10\%) and it was found to be $24.04 \%$ and $14.3 \%$ in other studies respectively. ${ }^{15,17}$ Lesser utilized antimicrobials were Amoxicillin (1\%), while other studies showed higher amoxicillin along with clavulanic acid usage $(11.16 \%) .{ }^{15}$ But, similar usage pattern to that of ours was found in few studies. ${ }^{2,8,11}$ The change in the drug utilisation pattern can be attributed to variation in disease trends from place to place and among different population.

There were $84.2 \%$ of the drugs were prescribed from Essential Drug list, WHO (2017) and National Essential Medicine List (2015) of India in our study and antimicrobials prescribed from the same were $90.9 \%$ and
$68 \%$ in other study as we select all the drugs from Essential Drug List to the Pharmacy at our Institution. ${ }^{15}$

WHO has reported that an average of only $60 \%$ of drugs were prescribed from EML in a survey of 35 countries of the world which is much less compared to our study $(84.2 \%) .{ }^{18}$ Drug utilization patterns have been found to differ not only among different countries but, also within a country in different institutions and in the same institution at different point of time probably because of variation in population and changing disease trends over a period. ${ }^{2,3}$

\section{CONCLUSION}

The results of this audit evaluated the drug utilization trends in the MICU at HIMS using WHO criteria. Majority of the drugs prescribed at our centre were from the WHO's Essential Drug Formulary as the drugs available at our Pharmacy are adopted from NLEM and procured. Frequent conduction of such studies helps us in listing $\mathrm{P}$ drugs and prepare the Standard Treatment Guidelines at Institutional level to improve the quality of life of the patients. Also, the audited prescription protocols can be used to guide rational use of drugs in the MICU.

\section{ACKNOWLEDGEMENTS}

Authors would like to thank the medical and nursing staff of Intensive care Unit for their enthusiasm in helping us and supporting us throughout the study period.

\section{Funding: No funding sources}

Conflict of interest: None declared

Ethical approval: The study was approved by the Institutional Ethics Committee

\section{REFERENCES}

1. Lee D, Bergmen U. Studies of utilization. In: Strom BC, editor. Pharmacoepidemiology. 1st Ed. New York: Churchill Livingstone; 1989:259-273.

2. Mittal N, Mittal R, Singh I, Shafiq N, Malhotra S. Drug utilization study in a tertiary care center: Recommendations for improving hospital drug dispensing policies. Indian $\mathbf{J}$ Pharm Sci. 2014;76(4):308-14.

3. Shinde RM, Kale A, Chube S, Sawant M. Drug utilization study in medical intensive care unit in a rural tertiary care teaching hospital in Maharashtra. Int J Med Sci Pub Heal. 2017;6(4):733-7.

4. Yamashita SK, Louie M, Simor AE, Rachlis A. Microbiological surveillance and parenteral antibiotic use in a critical care unit. Can $\mathbf{J}$ Infect Dis. 2000;11(2):107-11.

5. Williams A, Mathai AS, Phillips AS. Antibiotic prescription patterns at admission into a tertiary level intensive care unit in Northern India. J Pharm Bioallied Sci. 2011;3(4):531-6.

6. Benet LZ. Principles of prescription order writing and patients compliance instructions. In: Goodman AG, 
Rall TW. Nies AS Taylor P, (eds). Goodman and Gilman's The pharmacological basis of therapeutics. 8th Ed. NewYork: Pergamon Press Inc.; 1991:1640.

7. Srishyla MV, Naga Rani MA, Venkataraman BV: Drug utilization of antimicrobials in the in-patient setting of a tertiary hospital. Indian $\mathrm{J}$ Pharmacol. 1994;26:282-7.

8. Al-Zakwani I, Al-Thuhli M, Al-Hashim A, Al Balushi KA. Drug utilization pattern in an intensive care unit at a tertiary care teaching hospital in Oman. Asian J Pharma Clin Res. 2017 Feb 1;10(2):194-7.

9. Naqvi M, Chiranjeevi U, Shobha J. Prescription patterns of antibiotics in acute medical care unit of a tertiary care hospital in India. Int J Curr Microbiol App Sci. 2014;3:673-9.

10. Vandana A, Sanjaykumar B. Study of prescribing pattern of antimicrobial agents in medicine intensive care unit of a teaching hospital in central India. JAPI. 2012;60:20-3.

11. Patel MK, Barvaliya MJ, Patel TK, Tripathi C. Drug utilization pattern in critical care unit in a tertiary care teaching hospital in India. Iint J Crit Illn Inj Sci. 2013;3(4):250-5.

12. Gupta DR. Drug prescribing pattern in intensive care unit (ICU) in a tertiary care teaching hospital in Central India. Int J Pharm Bio Sci. 2015;6(3):325-9.

13. Mahajan B, Kaushal S, Chopra S. A drug utilization study of antimicrobial agents (AMAs) in the intensive care units (ICUs) at medical college hospital of North India. J K Sci. 2013;15:129-32.
14. Gangwar A, Kumar N, Kothiyal P. Antibiotic prescription and cost patterns in an intensive care unit. The pharma innovation. 2012;1:68-72.

15. Hedamba R, Doshi C, Darji NH, Patel B, Kumari V, Trivedi HR. Drug utilization pattern of antimicrobial drugs in intensive care unit of a tertiary care hospital attached with a medical college. Int $\mathrm{J}$ Basic Clin Pharmacol. 2016;5:169-72.

16. Saleh NA, Purya M, Hemadri M. Generic names or trade names prescribing practices of junior doctors. Kuwait Med J. 2001;33(2):153-5.

17. Bansal D, Mangla S, Undela K, Gudala K, D'Cruz S, Sachdev A, Tiwari P. Measurement of adult antimicrobial drug use in tertiary care hospital using defined daily dose and days of therapy. Indian J Pharm Sci. 2014;76:211-7.

18. World Health Organization. The world medicine situation. Geneva: WHO press, 2004:1-25. Available at:

http://apps.who.int/medicinedocs/pdf/s6160e/s6160e. pdf.

Cite this article as: Divyashree CR, Nalini GK, Suresh RM, Deepak P, Sahana GN, Nagaral JV, et al. A prospective observational study on drug utilization pattern in medical intensive care unit of a tertiary medical care hospital. Int J Basic Clin Pharmacol 2019;8:1356-60. 